\title{
To Achieve "Health for All" We Must Shift the World's Paradigm to "Primary Care Access for All"
}

\author{
Alain J. Montegut, MD
}

Since the early 1950s, the World Health Organization has proposed programs to promote primary health care around the world. From the 1978 Alma-Ata Declaration to the current promulgation of the Millennium Development Goals, the World Health Organization has tried to improve health in developing countries through a focus on disease-oriented (vertical) programs. The World Health Organization and other organizations have not focused on the horizontal role of primary care. The expectations created by these programs have not been met. Evidence demonstrates that the advent of health care through a base of primary care improves health better than through the traditional vertical diseaseoriented health programs used around the globe. The global "family" of family medicine must advocate for a shift from the current solutions to one in which the family doctor is part of a well-trained health care team that can function in networks that incorporate the vertical programs into a broad horizontal approach for better access to primary care. Perhaps in this way "health for all" can be achieved. ( $\mathrm{J}$ Am Board Fam Med 2007;20:514-517.)

As early as 1953, the Executive Board of the World Health Organization (WHO) stated that "assistance in the health field should be designed primarily to strengthen the basic health service of the country and to meet the most urgent problems affecting large sections of population." In 1978, in Alma-Ata, Kazakhstan, in the former Soviet Union, representatives of 134 countries came together under WHO and the United Nations Children's Fund to initiate the program "Health for All by the Year 2000." One major focus of this initiative was the provision of basic health care for all people through the inception of community-based efforts. ${ }^{2}$ Many of the programs that evolved were disease-focused, vertical projects related to sanitation, clean water, family planning, and immunizations. Despite some improvements in health, the

This article was externally peer reviewed.

Submitted 17 May 2007; revised 21 August 2007; accepted 28 August 2007.

From the Department of Family Medicine, Boston University Medical Center, Boston, MA.

Funding: none.

Conflict of interest: This author is on the Executive Committee of the World Organization of Family Doctors.

Corresponding author: Alain J. Montegut, MD, Director, Global Health Primary Care Initiative, Department of Family Medicine, Boston University Medical Center, Dowling 5, 1 Boston Medical Center Place, Boston, MA 02118 (E-mail: Alain.Montegut@bmc.org). goals set in 1978 were not met through the first 2 decades of action, at least with regard to establishing primary care services in most countries. ${ }^{3}$

To make attempts to further enhance the health for all, representatives of 189 countries met in 2000 at the United Nations and agreed on 8 millennium development goals. These include the eradication of extreme poverty and hunger, achieving universal primary education, the promotion of gender equality, the reduction of child mortality, the improvement of maternal health, the reversal of the spread of major diseases such as HIV/AIDS and malaria, improving the environment, and the development of global partnerships. ${ }^{4}$ The end point is 2015 . In 2006, however, although the United Nations Development Program reported some progress, there were still large gaps toward the hoped-for outcomes. $^{5}$

Why is a basic goal such as "health for all" so difficult to reach? Why is it so difficult to reduce child mortality or to improve maternal health? One could argue that there has not been enough investment of resources by the world's more affluent countries in the improvement of health, the reduction of poverty, and the improvement of human rights for those in the developing world. ${ }^{6}$ Although health services are one of the determinants of health, greater spending on health care 
is not necessarily associated with improved health outcomes. There is very strong evidence that access to comprehensive primary health care improves health outcomes. Therefore, increasing the ratio of primary care physicians compared with specialists is likely to further improve health outcomes. $^{7}$

Studies from Western industrialized countries have examined primary care according to 9 characteristics. These include ${ }^{8}$ :

- the extent to which the system regulates the distribution of resources throughout the country

- the mode of financing of primary care services

- the modal type of primary care practitioner

- the percentage of active physicians involved in primary care versus those in conventional specialty care

- the ratio of average professional earnings of primary care physicians compared with other specialists

- the requirement for cost sharing by patients

- the requirement for patient lists to identify the community served by practices

- 24-hour access arrangements

- strength of academic departments of primary care or general practice

In addition, 6 practice characteristics of the patients' experiences in receiving care have been found to be related to better health outcomes ${ }^{8}$ :

- First contact care

- Longitudinal care

- Comprehensive care

- Coordination of care

- Family-centered care

- Community orientation

A scoring system was developed that assigned a relative value to the countries being studied based on their level of primary care. This demonstrated that the countries with higher rankings in primary care had better health indicators and that those countries that had weak primary care infrastructures had higher costs and poorer outcomes. $^{8,9}$

There is an inverse relationship between primary care physician supply and especially between family physician supply and age-standardized mortality. ${ }^{10}$ Conversely, evidence demonstrates that an increase in the number of specialist physicians is associated with an increase in mortality, at least in a country well supplied with specialists (eg, the United States). ${ }^{10}$ There is also an association between primary care and infant outcomes. The greater the supply of primary care physicians, the lower the infant mortality and low birth weight percentage. $^{11}$

There have been numerous studies that have demonstrated that greater access to primary care leads to earlier detection of disease and a decrease in total mortality rates for specific diseases. ${ }^{12-16} \mathrm{In}$ addition, increased access to primary care results in better health outcomes and lower costs. ${ }^{17}$

Much of the evidence about the benefits of primary health care systems comes from industrialized countries, but there is some data from developing countries. ${ }^{18}$ Improvement in primary health care delivery systems is new to the developing world. If the countries most in need for health improvement will benefit from enhanced access to primary care, as has been demonstrated in industrialized countries, remains unclear. A model that provides a primary care physician with postgraduate training, such as a family physician, in each remote rural area of the world is unrealistic at this time. However, new models must evolve using the knowledge and skills of this well-trained physician to improve health in innovative ways through primary care networks that could include other primary care providers.

In 1994, after a joint meeting of the WHO and World Organization of Family Doctors (WONCA), a declaration was made stating that "to meet people's needs, fundamental changes must occur in the health care system, in the medical profession, and in medical schools and other institutions. The family doctor should have a central role in the achievement of quality, cost effectiveness, and equity in health care systems." ${ }^{19}$ The declaration went on to be even more specific, stating that "to fulfill this responsibility, the family doctor must be highly competent in patient care and must integrate individual and health care of the community." 19

Developing countries are now adopting the specialty of family medicine to improve health. NorthSouth partnerships are often a part of this development work. The integration of family medicine into health care delivery systems and the assistance that leads to these development projects now spans 
the globe, including the continents most in need, such as Africa, ${ }^{20,21}$ Asia, $^{22-24}$ and Latin America. ${ }^{25}$ The "family" of family medicine across the globe is reaching out to encourage and support the development of our specialty and to promote primary care.

The evidence suggests that it is through enhanced primary care that health can truly be improved. We must encourage the advance of health systems in the developing world that integrate the more common disease-oriented approach to health care delivery with a patient and population oriented approach that emphasizes access to a solid base of primary care providers. According to Chris Van Weel, in his incoming presidential address (Singapore July 2007), WONCA has called for " $15 \%$ by 2015 " as an appeal to the WHO and major health program donors to shift some of the funding allocated to the traditional, vertical disease-oriented programs to the horizontal primary care approach to improve access for those in need.

The "family" of family medicine must work toward this paradigm shift in health care delivery in countries of need. By supporting enhanced access to primary care networks of well trained providers we will improve health and reduce costs over time. By encouraging the integration of the disease-oriented global health programs into a wide network of well-trained primary care providers, these resources could perhaps be brought to a larger community through improved access to health care. The 6 practice characteristics of primary care ${ }^{8}$ harnessed to the resources now invested globally in health care could perhaps finally bring "Health to All."

\section{References}

1. World Health Organization. Handbook of resolutions and decisions, vol I, 1948-1972. Geneva (Switzerland): World Health Organization; 1973.

2. World Health Organization. Primary health care. Report of the International Conference on Primary Health Care, Alma-Ata, USSR, 6-12 September 1978. Geneva (Switzerland): World Health Organization; 1978.

3. World Health Organization. The World Health Report 1999: making a difference. Available at http:// www.who.int/whr/1999/en/whr99_en.pdf. Accessed 31 August 2007.

4. United Nations Department of Public Information. United Nations Millennium Development Goals.
Available at http://www.un.org/millenniumgoals/. Accessed 31 August 2007.

5. United Nations Development Indicators Unit. Millenium Indicators. Available at http://millenniumindicators.un.org/unsd $/ \mathrm{mi} / \mathrm{mi}$ _series_results.asp? rowId=561. Accessed 28 August 2007.

6. O’Neil, E. Awakening Hippocrates, a primer on health, poverty and global services. Chicago: American Medical Association; 2006.

7. Starfield B. Primary care: balancing health needs, services, and technology. New York: Oxford University Press; 1992.

8. Starfield B, Shi L. Policy relevant determinants of health: an international perspective. Health Policy 2002;60:201-18.

9. Starfield B. Primary care: is it essential? Lancet 1994; 344:1129-33.

10. Shi L, Macinko J, Starfield B, Wulu J, Regan J, Politzer R. The relationship between primary care, income inequality, and mortality in US States, 19801995. J Am Board Fam Pract 2003;16:412-22.

11. Shi L, Macinko J, Starfield B, et al. Primary care, infant mortality, and low birth weight in the states of the USA. J Epidemiol Community Health 2004;58: 374-80.

12. Ferrante JM, Gonzalez EC, Pal N, Roetzheim RG. Effects of physician supply on early detection of breast cancer. J Am Board Fam Pract 2000;13:40814.

13. Roetzheim RG, Pal N, van Durme DJ, et al. Increasing supplies of dermatologists and family physicians are associated with earlier stage of melanoma detection. J Am Acad Dermatol 2000:43(2 Pt 1): 211-8.

14. Roetzheim RG, Pal N, Gonzalez EC, et al. The effects of physician supply on the early detection of colorectal cancer. J Fam Pract 1999;48:850-8.

15. Campbell RJ, Ramirez AM, Perez K, Roetzheim RG. Cervical cancer rates and the supply of primary care physicians in Florida. Fam Med 2003;35:60-4.

16. Shi L, Macinko J, Starfield B, Xu J, Politzer R. Primary care, income inequality, and stroke mortality in the United States. A longitudinal analysis, 1985-1995. Stroke 2003;34:1958-64.

17. Franks P, Fiscella K. Primary care physicians and specialists as personal physicians. Health care expenditures and mortality experience. J Fam Pract 1998; 47:105-9.

18. Starfield B, Shi L, Macinko J. Contribution of primary care to health systems and health. Milbank Q 2005;83:457-502.

19. World Health Organization. Making medical practice and education more relevant to people's needs: the contribution of the family doctor. Geneva (Switzerland): World Health Organization; 1994.

20. Bakengesa E. Proceedings of the National Dialogue on the Future of Family Medicine, Makerere University, Makerere, Uganda, 8 June 2005. 
21. Lie DA, Boker JR, Lenahan PM, Dow E, Scherger JE. An international physician education program to support the recent introduction of family medicine in Egypt. Fam Med 2004;36:739-46.

22. Ministry of Health China (2001). The Compendium of Developing Health Manpower from 2001 to 2015. Available at http://www.moh.gov.cn/newshtml/ 8082.htm. Accessed 29 August 2007.

23. Kanashiro J, Hollaar G, Wright B, Nammavongmixay K, Roff S. Setting priorities for teaching and learning: an innovative needs assessment for a new Family Medicine program in Lao PDR. Acad Med 2007;82:231-7.

24. Montegut AJ, Cartwright CA, Schirmer JM, Cummings S. An international consultation: the development of family medicine in Vietnam. Fam Med 2004; 36:352-6.

25. Thompson R, Spann SJ. Faculty development for foreign teachers of family medicine. Fam Med 1997; 29:435-8. 